\title{
La Palmera de Coateco
}

\author{
Por el Sr. Jesús Silva.
}

Entre las palmeras silvestres que se encuentran a lo largo de la Costa Chica del Estado de Oaxaca, principalmente en el Distrito de Juquila y a unos 400 metros sobre el nivel del mar, se encuentra una conocida regionalmente como "Palma de Coateco", cuyo tallo está cubierto de espinas amarillas, y que tal vez pudiera ser la Åcanthorrhiza Mocinni (H. B. K.) B. et Hooker o una variedad de ésta.

Se trata de una plamera de 1.50 a $3 \mathrm{~m}$. de altura, con las hojas en forma de abanico. Hay un lugar que por tenerla en gran abundancia se llama "El Coatecal".

La denominación de "Palma de Coateco" se debe a que la parte comestible se llama "coateco". Es la yema terminal que aparece antes de la floración y que hace que el tallo se ensanche algo en la extremidad, lo que sucede a mediados o a fines de la estación de lluvias; los costeños cortan con un filoso machete a cada palmera que "está en su punto" un trozo como de $20 \circ 25 \mathrm{~cm}$.; los despojan de sus hojas y los ponen asar en la lumbre o a hervir en agua como se hace con los elotes. Luego que están lo suficientemente cocidos los abren y sacan del interior una substancia feculenta parecida a la de la alcachofa, de sabor agradable, aunque algo amargo.

Lo único lamentable es que el corte de la yema significa la muerte de la palma, y no se ha extinguido la especie gracias a que es extraordinariamente abundante. Estas palmas producen "chobaguines" o sean especie de telas fibrosas que se usan para "sudaderos" de bestias de carga. Además, se utilizan las hojas tiernas para hacer escobas. 


\section{Notas breves}

Nuestro consocio el Sr. Ing. Gabriel Itié, profesor de la Escuela Nacional de Agricultura, ha comenzado a publicar un Glosario de Botánica, que sin duda será de mucha utilidad no solamente en esa Escuela, sino en todos los Centros donde se estudia la Botánica.

El Prof. Maximino Martínez ha escrito una monografía sobre los Abies Mexicanos, que será publicada próximamente en los Anales del Instituto de Biología, de la Universidad Nacional

El Sr. E. E. Loock, del Departamento Forestal de Sud-Africa vendrá a México a fines de este año para continuar sus estudios sobre los pinos. Además, traerá semillas que conviene introducir aquí.

Los. Sres. Helmuth O Wagner y Hans Lenz han publicado un interesante libro intitulado "El Bosque y la Conservación del Suelo". En dicha obra exponen de una manera sencilla y a! alcance de todos, muchos problemas de gran importancia relacionados con los bosques, la erosión, el clima y otros asuntos.

El Sr. C. Halbinger está iniciando los arreglos para conseguir que el antiguo Jardín de Huaxtepec sea declarado Parque Nacional y proporie que nuestra Sociedad cultive en ese lugar plantas de particular interés.

El Arnold Arboretum nos envió algunas semillas de Metasequoia glyptostroboides, recientemente descubireto en China y que se creía extinguido. Unas cuantas semillas han germinado y hay la esperanza de que se logren.

El Sr. Prof. Casiano Conzatti continúa publicando su obrá "Flora Taxonómica Mexicana, la que constará de 12 volúmenes y tiene ya hechos los arreglos para que la obra se publique íntegramente. El precio de cada tomo es de 10 pesos dentro del país y de 2.25 dólares en el extranjero. La dirección del Sr. Conzatti es Calle de Gómez Farías 3, Oaxaca, Oax.

Nuestros asociados Ing. Gustavo A. Benavides y Dr. Blas P. Reko han hecho un viaje al Estado de Coahuila y próximamente publicarán el resultado de sus observaciones botánicas.

El Dr. Harold Moldenke, del Jardín Botánico de Nueva York, nos visitará el próximo mes de noviembre. 